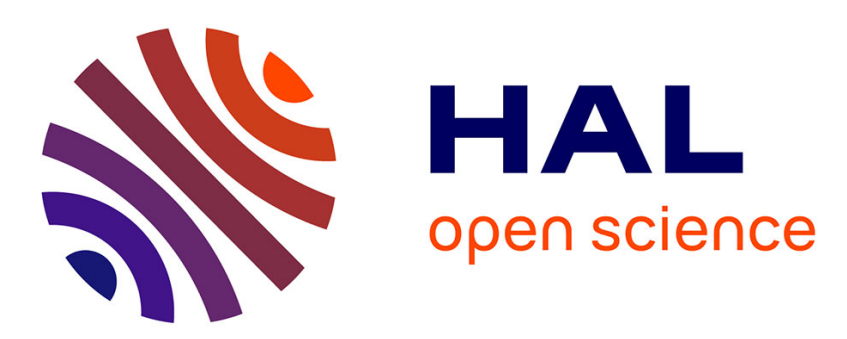

\title{
Facteurs de production du lait et caractéristiques des fromages. I. Influence des facteurs de production sur l'aptitude à la coagulation des laits de troupeaux
} B Martin, Jb Coulon

\section{- To cite this version:}

B Martin, Jb Coulon. Facteurs de production du lait et caractéristiques des fromages. I. Influence des facteurs de production sur l'aptitude à la coagulation des laits de troupeaux. Le Lait, 1995, 75 (1), pp.61-80. hal-00929419

\section{HAL Id: hal-00929419 https://hal.science/hal-00929419}

Submitted on 1 Jan 1995

HAL is a multi-disciplinary open access archive for the deposit and dissemination of scientific research documents, whether they are published or not. The documents may come from teaching and research institutions in France or abroad, or from public or private research centers.
L'archive ouverte pluridisciplinaire HAL, est destinée au dépôt et à la diffusion de documents scientifiques de niveau recherche, publiés ou non, émanant des établissements d'enseignement et de recherche français ou étrangers, des laboratoires publics ou privés. 


\title{
Facteurs de production du lait et caractéristiques des fromages. I. Influence des facteurs de production sur l'aptitude à la coagulation des laits de troupeaux ${ }^{1}$
}

\author{
B Martin *, JB Coulon
}

Laboratoire adaptation des herbivores aux milieux, INRA, 63122 Saint-Genès-Champanelle, France

(Reçu le 25 août 1994 ; accepté le 22 novembre 1994)

\begin{abstract}
Résumé - Les variations de la composition chimique et de l'aptitude à la coagulation des laits de troupeaux ( $n=271$ ) ont été observées à l'échelle de la quinzaine pendant 18 mois chez 6 producteurs de fromage fermier (reblochon) du département de la Haute-Savoie (France). Elles ont été mises en relation avec les caractéristiques physiologiques et génétiques des animaux et les pratiques d'alimentation hivernales et estivales. La fermeté du gel a été fortement corrélée au taux de protéines coagulables $\left(R^{2}=0,72\right)$. Elle a varié sous l'effet du stade physiologique moyen du troupeau $\left(R^{2}=\right.$ 0,50 ) et les gels les plus fermes ont été associés aux niveaux d'apports énergétiques les plus élevés. A même taux de protéines coagulables, les gels les plus fermes provenaient d'une part des troupeaux caractérisés par les fréquences alléliques du variant $B$ de la caséine $\kappa$ les plus élevées, et d'autre part de la période de pâturage où les taux de calcium ont été plus élevés. Le temps de gélification a varié de façon parallèle au pH initial du lait $\left(R^{2}=0,50\right)$. II a diminué de $20 \%$ entre le $6^{e}$ et le $9^{\circ}$ mois de lactation et a été plus court de $13 \%$ lorsque la fréquence allélique du variant $B$ de la $\beta$-lactoglobuline était plus faible de $20 \%$. La variabilité du temps de gélification des laits a également été associée à la nature des aliments et aux modalités de leur distribution.
\end{abstract}

aptitude à la coagulation / alimentation / stade physiologique / variant des lactoprotéines / saison

Summary - Milk production and cheese characteristics. I. Influence of milk production conditions on herd milk clotting ability. Herd milk chemical composition and clotting ability $(\mathrm{n}=271)$ have been analysed every 2 weeks over an 18-month period in 6 dairy farms producing farmhouse Reblochon cheese from the Haute-Savoie area (France). Variations have been related to cow's characteristics (lactation stage and milk protein genetic variants) and feeding practices observed during the

1 Travail réalisé dans le cadre du programme de recherche-développement du groupement d'intérêt scientifique des Alpes-du-Nord.

*Adresse actuelle : GIS-SUACI Alpes-du-Nord, 11, rue Métropole, 73000 Chambéry, France. 
winter and summer seasons. These analyses showed an important variability of both curd firmness and rennet clotting time. They varied respectively between 30 to $48 \mathrm{~mm}$ and 8 to $22 \mathrm{~min}$. Curd firmness was linked first to herd mean lactation stage $\left(R^{2}=0.50\right)$. In winter as well as in summer, stronger curds were associated with feeding practices allowing high energy supply. These effects are mostly explained by the parallel variation of milk casein content, strongly correlated to curd firmness $\left(R^{2}=0.72\right)$. For the same casein content, residual variability was linked to $k$-casein $B$ variant frequency in the herd and to the season of the year. An increase of $20 \%$ of $k$-casein frequency in the herd led to a rise of curd firmness equivalent to that expected from an increase of $1 \mathrm{~g} / \mathrm{kg}$ of protein content. Turning out to pasture had a beneficial effect on curd firmness. This beneficial effect of the summer season is partly explained by the Ca content rise observed during this period. Milk casein content, season of the year and $K$-casein $B$ variant herd frequency, when they are introduced into a linear model, explain $82 \%$ of curd firmness variability. Milk clotting time was strongly correlated to natural milk pH $\left(F^{2}=0.50\right)$. A 20\% decrease has been observed between the 6 th and 9th lactation month and clotting time was $13 \%$ shorter when $\beta$-lactoglobulin B variant frequency was $20 \%$ lower in the herd. Clotting time variability was associated too with some feeding practices such as kind of feed or distribution mode. Nevertheless, neither herd milk clotting time nor natural $\mathrm{pH}$ variations of milk are as well explained as milk curd firmness variations.

\section{milk clotting ability / feeding / lactation stage / season of the year/genetic protein variant}

\section{INTRODUCTION}

La coagulation du lait par la présure est la première étape de la réalisation de la plupart des fromages. Le comportement du lait lors de la coagulation joue un rôle important sur le bon déroulement des étapes ultérieures de la fabrication fromagère qui sont souvent considérées comme sa simple continuation (Lawrence et al, 1984). En particulier, les laits qui présentent une coagulation défectueuse s'égouttent difficilement et sont à l'origine de diminutions du rendement fromager : ils conduisent souvent à des fromages trop humides, et d'affinage difficile (Mocquot et al, 1954 ; Okigbo et al, 1985 ; Remeuf et al, 1991).

L'aptitude à la coagulation du lait dépend en partie de sa composition chimique. Les principales relations entre les différents critères de la coagulation et la composition chimique du lait sont maintenant bien connues. Le comportement d'un lait lors de la coagulation varie essentiellement en fonction du taux de protéines (Schaar, 1984 ; Vertès et Hoden, 1989 ; Remeuf et al, 1991 ; Macheboeuf et al, 1993) dont les facteurs de variations liés à l'alimentation sont bien connus (Sutton, 1989 ; Coulon et Rémond, 1991). L'aptitude à la coagulation du lait dépend également de la nature des variants génétiques des protéines dont l'influence sur la coagulation a fait l'objet d'un nombre important d'études (Morini et al, 1979 ; NgKwai-Hang et al, 1987 ; Grosclaude, 1988 ; Aléandri et al, 1990 ; Delacroix-Buchet et al, 1993). Elle varie aussi largement en fonction du $\mathrm{pH}$ initial du lait et de sa teneur en éléments minéraux pour lesquels en revanche, les facteurs de variation propres à l'animal ou au milieu sont moins connus (Anderson, 1992).

L'influence directe de certains facteurs de production du lait sur son aptitude à la coagulation a été étudiée en conditions expérimentales sur des laits individuels. II s'agit en particulier des facteurs alimentaires (Grandison et al, 1985b ; Vertès et Hoden, 1989 ; Macheboeuf et al, 1993), saisonniers (Grandison et al, 1984a ; Macheboeuf et al, 1993) ainsi que des interactions avec les facteurs génétiques (Macheboeuf et al, 1993). Les effets des différents facteurs mis en évidence en conditions expérimentales sur des laits individuels ont cependant rarement été abordés en exploitation et sur le lait de mélange de plusieurs 
animaux. Des variations considérables de l'aptitude à la coagulation du lait des troupeaux sont pourtant fréquemment observées sur le terrain et leur interprétation est parfois délicate (Grandison et al, 1985b ; Coulon et al, 1988 ; Martin et Coulon, 1991).

L'objectif de ce travail a été d'analyser, chez des producteurs de fromages fermiers, et sur des laits de troupeaux, l'ensemble des facteurs de variations de la composition chimique et de l'aptitude à la coagulation afin d'une part de préciser et quantifier leur rôle respectif et d'autre part d'étudier leurs interactions lorsqu'ils sont mis en œuvre sur le terrain. L'ensemble des facteurs de variation des caractéristiques des fromages affinés, liés aux caractéristiques du lait ou à la technologie mise en œuvre seront abordés dans un article ultérieur (Martin et Coulon, 1995).

\section{MATÉRIEL ET MÉTHODES}

\section{Les exploitations (tableau I)}

Les 6 producteurs de reblochon fermier chez qui cette étude a été réalisée sont localisés dans la vallée de Thônes en Haute-Savoie (France), à une altitude variant de 700 à $1200 \mathrm{~m}$. Les troupeaux étaient composés de 22 à 66 vaches laitières essentiellement de race Abondance ( $88 \%$ de l'effectif total). La production laitière moyenne des 6 troupeaux a varié entre 3300 et $5550 \mathrm{~kg} / \mathrm{vache} / \mathrm{an}$ et les taux butyreux et protéiques ont été compris respectivement entre 36,0 et $39,1 \mathrm{~g} / \mathrm{kg}$ et entre 31,0 et $32,7 \mathrm{~g} / \mathrm{kg}$ (résultats Contrôle Laitier 1991 et 1992). Au cours des 4 notations réalisées, l'état corporel des animaux a été en moyenne satisfaisant $(2,5 / 5)$ bien que des différences importantes entre troupeaux aient été relevées : les notes moyennes se répartissent entre 1,9 et 2,8/5. En hiver (novembre à mai), les animaux étaient nourris exclusivement avec des rations à base de foin, complémentées avec des aliments concentrés du commerce. La mise à l'herbe a été réalisée entre le 20/04 et le $20 / 05$ sur les prairies permanentes disponibles autour du siège des exploitations. Cinq des 6 producteurs disposaient d'un alpage individuel où les vaches ont séjourné entre 100 et 135 jours à partir de la mi-mai ou de la mi-juin selon les producteurs.

\section{Données recueillies}

Les données ont été recueillies au cours de passages bimensuels dans les 6 exploitations entre avril 1991 et octobre 1992. Elles concement d'une part les caractéristiques des animaux et les pratiques d'alimentation, et d'autre part les caractéristiques physico-chimiques et rhéologiques des laits des cuves.

\section{Caractéristiques des troupeaux et pratiques d'alimentation}

Les caractéristiques des troupeaux ont été décrites par le stade physiologique moyen (défini comme le stade physiologique de chaque animal pondéré par la proportion du lait de la cuve qu'il a réellement produite), la proportion de lait produite par les animaux en tout début de lactation (jour 1 à 60), en fin de lactation (240 jours et plus), par les vaches laitières gravides, et audelà du $180^{\circ}$ jour de gestation. Par ailleurs, les pourcentages du lait de la cuve provenant des animaux possédant l'allèle $B$ de la caséine $\kappa$ et de la $\beta$-lactoglobuline ont également été calculés en affectant un coefficient de 1/2 aux animaux hétérozygotes. L'état corporel des animaux a été noté individuellement dans les 6 exploitations en début et en fin d'hiver (avril 1991, novembre 1991, mai 1992 et octobre 1992).

Les pratiques d'alimentation du troupeau ont été notées à partir d'un entretien bimensuel avec les producteurs, concernant principalement, la nature, la quantité et la qualité des fourrages secs et des aliments concentrés distribuées, ainsi que les modalités de leur distribution. Les quantités de chaque lot de fourrages secs distribués ont été appréhendées à l'échelle du troupeau et les quantités d'aliments concentrés distribuées ont été mesurées individuellement. En été, un planning des surfaces pâturées était mis à jour lors de chaque passage dans les exploitations. Les parcelles utilisées sur le siège de l'exploitation et sur l'alpage avaient fait l'objet d'un zonage préalable et le type dominant de chaque parcelle (qui traduit sa composition floristique) avait été attribué 
Tableau I. Principales caractéristiques des exploitations.

Main farms' characteristics.

\begin{tabular}{|c|c|c|c|c|c|c|}
\hline & \multicolumn{6}{|c|}{ Producteur } \\
\hline & 1 & 2 & 3 & 4 & 5 & 6 \\
\hline Main d'œuvre (UTH) & 1,0 & 6,0 & 3,0 & 3,0 & 2,0 & 2,5 \\
\hline Âge des chefs d'exploitation (ans) & 40 & 35 & 35 & 38 & 32 & 40 \\
\hline \multicolumn{7}{|l|}{ Siège de l'exploitation } \\
\hline $\begin{array}{l}\text { SAU (ha) } \\
\text { Altitude (m) }\end{array}$ & $\begin{array}{c}18 \\
700\end{array}$ & $\begin{array}{c}28 \\
1050\end{array}$ & $\begin{array}{c}23 \\
1050\end{array}$ & $\begin{array}{c}17 \\
900\end{array}$ & $\begin{array}{c}4 \\
1120\end{array}$ & $\begin{array}{c}50 \\
1200\end{array}$ \\
\hline Alpage & Oui & Oui & Oui & Oui & Oui & Non \\
\hline $\begin{array}{l}\text { Surface (ha) } \\
\text { Altitude (m) }\end{array}$ & 40 & 40 & 20 & 35 & 13 & 1 \\
\hline $\begin{array}{l}\text { minimale } \\
\text { maximale }\end{array}$ & $\begin{array}{l}1400 \\
1550\end{array}$ & $\begin{array}{l}1380 \\
1450\end{array}$ & $\begin{array}{l}1000 \\
1150\end{array}$ & $\begin{array}{l}1300 \\
1500\end{array}$ & $\begin{array}{l}1100 \\
1350\end{array}$ & $\begin{array}{l}1 \\
1\end{array}$ \\
\hline Date de montée à l'alpage & $8 / 6$ & $20 / 5$ & $1 / 6$ & $5 / 6$ & $10 / 5$ & 1 \\
\hline Date de descente de l'alpage & $25 / 9$ & $1 / 10$ & $10 / 9$ & $1 / 10$ & $1 / 9$ & 1 \\
\hline Nbre de jours d'alpage & 105 & 130 & 100 & 115 & 135 & 1 \\
\hline
\end{tabular}

Troupeau (données du Contrôle laitier campagne 91/92)

$\begin{array}{lcccccc}\text { Nombre de vaches présentes } & 21,9 & 66,4 & 45,3 & 29,4 & 25,0 & 34,0 \\ \text { Race Abondance (\%) } & 86 & 100 & 75 & 97 & 82 & 82 \\ \text { Numéro moyen de lactation } & 2,9 & 3,0 & 3,4 & 3,6 & 2,7 & 3,2 \\ \text { Intervalle vêlage-vêlage (jours) } & 421 & 381 & 373 & 368 & 368 & 380 \\ \text { Production individuelle (kg/an) } & 3305 & 5550 & 5450 & 4095 & 4440 & 4290 \\ \text { Taux butyreux }(\mathrm{g} / \mathrm{kg}) & 37,5 & 39,1 & 36,0 & 36,5 & 37,3 & 36,2 \\ \text { Taux protéique }(\mathrm{g} / \mathrm{kg}) & 31,3 & 32,7 & 31,4 & 31,0 & 31,3 & 31,1 \\ \text { Répartition des vêlages (\% de l'effectif) } & & & & & & \\ \quad \text { Juin-août } & 35 & 18 & 30 & 25 & 8 & 20 \\ \quad \text { Sept-nov } & 32 & 48 & 38 & 37 & 55 & 42 \\ \quad \text { Dec-fev } & 25 & 16 & 19 & 18 & 25 & 23 \\ \quad \text { Mars-mai } & 7 & 17 & 12 & 20 & 12 & 15 \\ \quad \text { État corporel (moyenne de 4 notations) } & 1,9 & 2,8 & 2,6 & 2,4 & 2,4 & 2,3\end{array}$

à l'ensemble de la parcelle selon la typologie proposée par Bornard (1992). Au cours de chaque passage dans les exploitations, ces entretiens étaient complétés par des observations concernant principalement la présence ou l'absence de refus de fourrages secs et les modalités de distribution des aliments ainsi que, pendant la période de pâturage, le stade végétatif de l'herbe offerte. Ce dernier a été appréhendé, lors du premier passage par le stade du dactyle exprimé en jours par rapport au début de la montaison, et lors des passages ultérieurs, par le temps de repousse entre 2 passages successifs exprimé en jours. 


\section{Laits des troupeaux}

Les échantillons de lait de troupeau ont été prélevés dans la cuve de fabrication juste avant l'emprésurage, exclusivement lors de la traite du matin. Ils ont été additionnés de $2000 \mathrm{UI} / \mathrm{I}$ de pénicilline (Spénicilline G), destinée à stopper le développement des bactéries lactiques entre le moment du prélèvement et le moment des analyses. Les tests d'aptitude à la coagulation et la séparation de la phase soluble et colloïdale du lait ont été réalisés dès l'arrivée des échantillons au laboratoire (environ $3 \mathrm{~h}$ après le prélèvement). Les échantillons de lait destinés aux autres analyses ont été additionnés de bichromate de potassium (concentration finale $0,06 \%$ ) et conservés jusqu'aux analyses à $4^{\circ} \mathrm{C}$.

\section{Analyses physico-chimiques et bactériologiques}

La teneur du lait en matières grasses a été déterminée par la méthode acido-butyrométrique de Gerber (AFNOR 1971, norme NF 04-210). La teneur en matières protéiques a été déterminée par la méthode du Noir Amido (AFNOR, 1971 norme VF 04-216). Le dosage des protéines non coagulables a été réalisé à partir d'un filtrat obtenu par séparation de la phase coagulable et non coagulable par la présure. Les protéines du lactosérum ainsi obtenu ont été dosées par la méthode du Noir Amido et la teneur du lait en protéines coagulables a été calculée en faisant la différence entre les teneurs en matières protéiques totales et non coagulables. Le calcium a été dosé par la méthode fluorométrique à l'aide d'un calcimètre Corning 940 ; sa fraction totale était déterminée sur du lait et sa fraction soluble sur le filtrat préparé pour le dosage des protéines non coagulables. La teneur en urée des laits a été déterminée par la méthode colorimétrique à la diacétylmonoxamine, sur un filtrat obtenu après déprotéinisation du lait par le TCA 15\% (Michel, 1971). Le pH initial du lait entier a été déterminé dès son arrivée au laboratoire, à la température de $20^{\circ} \mathrm{C}$, à l'aide d'un pHmètre KNICK (modèle PORTAMESS 752) équipé d'une électrode Ingold (Lot 406).

L'identification des variants génétiques de la $\beta$ lactoglobuline et des caséines $\alpha-S, \beta$ et $\kappa$ du lait de l'ensemble des animaux des 6 producteurs a été réalisée par isoélectrofocalisation selon la méthode proposée par Siebert et al (1985).

\section{Tests technologiques}

L'aptitude du lait à la coagulation par la présure a été déterminée à l'aide d'un Formagraph (Société Foss-Electric) selon la méthode proposée par McMahon et Brown (1982). Les analyses ont été réalisées en double. Le lait entier ( $10 \mathrm{ml})$, a été emprésuré à une température de $35^{\circ} \mathrm{C}$ à l'aide d'un extrait de présure titrant à $520 \mathrm{mg}$ de chymosine active par litre (dilution finale dans le lait : 3,2 pour 1000 ). Lors de chaque analyse, un lait de référence (lait reconstitué à partir d'une poudre de lait étalon fournie par l'INRA de Poligny) a été testé afin de vérifier la répétabilité de la méthode.

Le temps de gélification ( $R$ exprimé en min), le temps de raffermissement (K20 exprimé en min) et la fermeté du gel mesuré 30 min après l'emprésurage ( $A 30$ exprimé en $\mathrm{mm}$ ) et après un raffermissement égal au temps de gélification (AR exprimé en $\mathrm{mm}$ ) ont été déterminés sur un échantillon de lait à $\mathrm{pH}$ initial, à pH standardisé et à temps de gélification ajusté à $15 \mathrm{~min}$ en modifiant la dose de présure.

Un test d'estimation du rendement fromager du lait a été réalisé par centrifugation d'un caillé obtenu à partir d'un échantillon de lait entier, emprésuré à pH initial. Cette analyse, qui permet d'avoir une bonne estimation des rendements réels obtenus en cuve, a été réalisée selon la méthode décrite par Hurtaud et al (1991). Le rendement frais correspond au poids de caillè rapporté au poids de lait mis en oeuvre. Le rendement en matière sèche est le rendement frais multiplié par l'extrait sec du caillé.

\section{Traitement des données}

Les 271 laits de troupeaux analysés chez les 6 producteurs ont fait l'objet d'une première description à l'aide d'une analyse factorielle des correspondances (AFC, logiciel ADDAD) dans laquelle seuls les descripteurs de la coagulation et du rendement fromager obtenu par centrifugation ont participé à la construction des axes. Compte tenu des fortes liaisons entre les différents paramètres décrivant la coagulation, on a choisi de ne retenir pour les analyses, que les descripteurs de la coagulation les plus indépendants, à savoir le temps de gélification mesuré à $\mathrm{pH}$ initial et la fermeté du gel mesurée après un raffermissement égal au temps de gélification. La composition chimique des laits et les variables décrivant les troupeaux et les pratiques 
des éleveurs ont été introduites comme variables supplémentaires. L'influence des pratiques des éleveurs sur l'aptitude à la coagulation des laits a été étudiée à partir d'un sous-ensemble de laits pour lesquels le stade de lactation moyen des troupeaux a été compris entre le $110^{\circ}$ et le $160^{\circ}$ jour de lactation $(n=131)$. Pour cela, une classification ascendante hiérarchique $(\mathrm{CAH}$, logiciel $A D D A D)$ des laits a été réalisée à partir de leurs coordonnées sur les 3 premiers axes de l'AFC (expliquant $43 \%$ de l'inertie globale). Les variables explicatives associées aux laits des différentes classes ont été décrites et comparées par analyse de variance pour les variables quantitatives et par le test du Khi-deux pour les variables qualitatives (SAS, 1987).

\section{RÉSULTATS}

\section{Caractéristiques des laits de cuve (tableau II)}

L'effectif de vaches dont le lait était utilisé pour la fabrication a été compris entre 5 et 43 et le stade de lactation moyen des troupeaux a varié entre 63 et 277 jours. Le lait produit par les animaux possédant l'allèle $B$ de la caséine $\kappa$ et l'allèle $B$ de la $\beta$-lactoglobuline a représenté respectivement $52 \%$ et $47 \%$ du lait des cuves.

Tableau II. Caractéristiques moyennes des laits des troupeaux $(n=271)$.

Average herd milks characteristics $(n=271)$.

Moyenne Minimum Maximum Écart type

Lait ( $\mathrm{kg} / \mathrm{vache/traite)}$

Taux butyreux $(\mathrm{g} / \mathrm{kg})$

Taux protéique $(\mathrm{g} / \mathrm{kg})$

Protéines coagulables $(\mathrm{g} / \mathrm{kg})$

Taux butyreux/Taux protéique

Protéines coagulables (\%TP)

Calcium total $(\mathrm{g} / \mathrm{kg})$

Calcium colloïdal ( $\mathrm{g} / \mathrm{kg}$ )

Calcium colloïdal/Prot coag ( $x 100)$

Cellules $\left(x 10^{3} / \mathrm{ml}\right)$

Flore totale $\left(\mathrm{x} 10^{6} / \mathrm{ml}\right)(1)$

Flore coliforme $(/ \mathrm{ml})(1)$

$\mathrm{pH}$ initial

Temps de gélification ( $\mathrm{min}$ )

Temps de raffermissement ( $\mathrm{min}$ )

Fermeté du gel $(\mathrm{mm})$

Rendement sec (\%)

Extrait sec du caillé (\%)

Effectif des troupeaux

Stade de lactation moyen du troupeau (jours)

$\%$ d'animaux en début de lactation ( $<60$ jours)

$\%$ d'animaux en fin de lactation ( $>240$ jours)

Allèle $B$ de la caséine $\kappa(\%)$

Allèle $B$ de la $\beta$-lactoglobuline (\%)
8,6

35,7

31,6

25,0

1,13

79,2

1,20

0,80

3,19

\section{9}

1,6

125

6,66

13,5

5,7

37,4

8,1

23,0

23

137

24

14

52

47
5,0

26,6

28,5

22,5

0,88

76,0

1,07

0,68

2,62

20

0,02

$<10$

6,52

7,9

2,5

30,3

6,4

18,4

\section{5}

63

0

0

37

23
12,5

48,4

36,2

28,7

1,46

80,9

1,39

0,95

3,67

400

6,3

$10^{5}$

6,80

21,75

10,5

48,3

10,3

28,8

43

277

73

93

71

68
1,7

3,5

1,6

1,25

0,09

0,7

0,06

0,05

0,18

58

0,11

10

0,05

1,85

1,1

2,9

0,7

1,8

\section{8}

43

17

16

7

\footnotetext{
1 Moyenne logarithmique, laits ensemencés en levains

1 Logarithmic mean values, milks added with starters.
} 
La variabilité des caractéristiques des 271 laits de cuve analysés a été particulièrement importante (tableau II). Les taux butyreux et protéiques ont varié respectivement entre 26,6 et $48,4 \mathrm{~g} / \mathrm{kg}$ et entre 28,5 et $36,2 \mathrm{~g} / \mathrm{kg}$. Pour $80 \%$ des laits analysés, les protéines coagulables ont représenté entre 78 et $80 \%$ des protéines totales et les numérations cellulaires ont été inférieures à $200000 / \mathrm{ml}$ pour $95 \%$ des comptages réalisés. Les temps de gélification et de raffermissement mesurés à $\mathrm{pH}$ initial ont varié respectivement entre 7,9 et $21,7 \mathrm{~min}$ et entre 2,5 et $10,5 \mathrm{~min}$ et la fermeté du gel mesurée après un raffermissement égal au temps de gélification a été comprise entre 30,3 et $48,3 \mathrm{~mm}$.

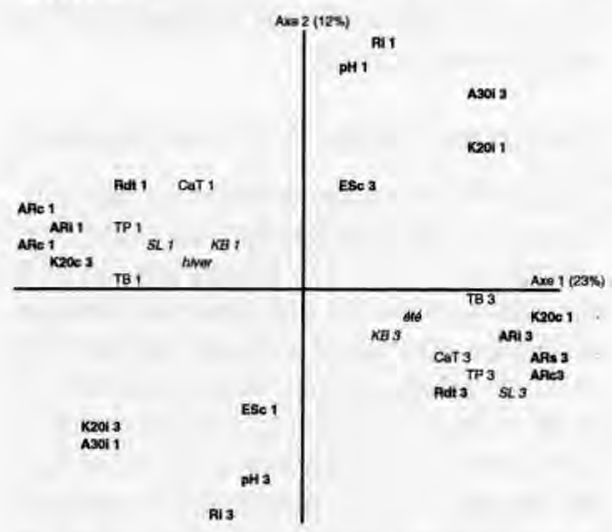

Fig 1. Représentation simplifiée du plan factoriel 1 - 2 de l'AFC ( $35 \%$ de l'inertie) réalisée à partir de l'aptitude à la coagulation des laits $(n=$ 271). Variables: (R) temps de gélification, (K20) temps de raffermissement, (A30) fermeté du gel (30 min), (AR) fermetè du gel, (TB) taux butyreux, (TP) taux protéique, (CaT) calcium total, (SL) stade de lactation moyen des troupeaux. (1) modalité faible, (3) modalité forte, (i) $\mathrm{pH}$ initial, (S) $\mathrm{pH}$ standardisé, (c) temps de gélification ramené à $15 \mathrm{~min}$.

Simplified representation of factorial plan 1-2 of CFA considering milk clotting ability. (R) Rennet clotting time, (K20) curd firming time, (A30) curd firmness (30 $\mathrm{min})$, (AR) curd firmness, (TB) fat content, (TP) protein content, (CaT) calcium content, (SL) herd average lactation stage. (1) low modality, (3) strong modality, (i) natural $\mathrm{pH}$, (s) standardised $\mathrm{pH}$, (c) rennet clotting time $15 \mathrm{~min}$.

\section{Facteurs de variation de l'aptitude à la coagulation des laits de troupeau}

\section{Ensemble des laits}

Le plan factoriel 1-2 de l'AFC réalisée à partir des variables décrivant l'aptitude à la coagulation des laits, est représenté sur la figure 1. Le premier axe factoriel $(23 \%$ de l'inertie globale) permet d'opposer les laits qui se raffermissent rapidement et conduisent à un gel ferme aux laits dont le raffermissement est lent et qui sont à l'origine d'un gel mal structuré. Le deuxième axe de l'AFC ( $12 \%$ de l'inertie globale) oppose les laits dont le $\mathrm{pH}$ est faible, la gélification est rapide et qui, dans une moindre mesure, s'égouttent facilement, aux laits moins acides, dont la gélification est plus lente et qui s'égouttent plus difficilement. Les rendements fromagers, le temps de raffermissement et la fermeté du gel mesurée 30 min après l'emprésurage ( $\mathrm{pH}$ initial) sont bien représentés sur ces 2 axes. La projection sur le premier plan factoriel des modalités des variables supplémentaires décrivant la composition chimique des laits permet d'opposer, sur l'axe représentant la fermeté du gel (axe 1), les laits riches en protéines, en matières grasses et en calcium aux laits dont le taux protéique, le taux butyreux et le taux de calcium sont plus faibles. Sur l'ensemble des laits analysés, le temps de gélification a été corrélé principalement à son $\mathrm{pH}$ initial (fig 2), qui permet d'expliquer $50 \%$ de sa variabilité et les seules variations de la teneur des laits en protéines (totales ou coagulables) permettent d'expliquer $72 \%$ de la variabilité de la fermeté du gel (fig 3 ). Cette liaison a été indépendante du taux de leucocytes dont la variabilité a été faible ou du taux butyreux dont la variabilité a par contre été particulièrement importante. Ces 2 facteurs, lorsqu'ils sont introduits dans un modèle linéaire, ne permettent pas d'améliorer la prévision de la fermeté du gel. 


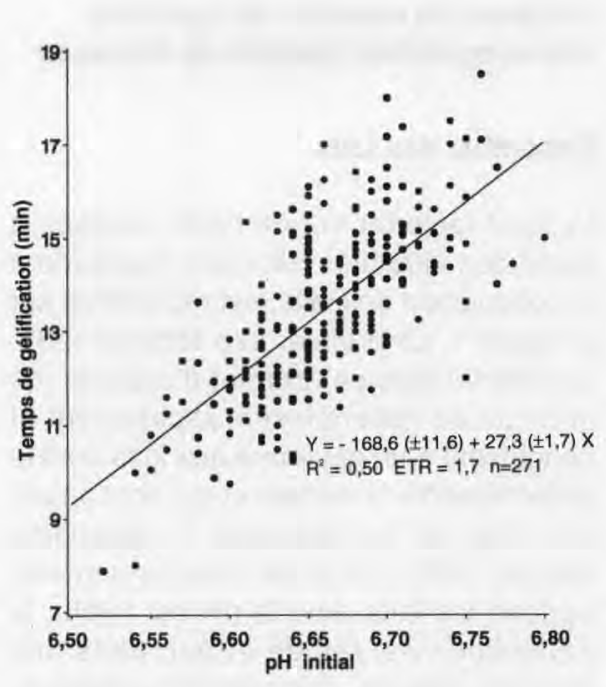

Fig 2. Relation entre le $\mathrm{pH}$ initial du lait et le temps de gélification (mesuré à $\mathrm{pH}$ initial) des laits des troupeaux.

Relationship between herd milk natural $\mathrm{pH}$ and rennet clotting time.

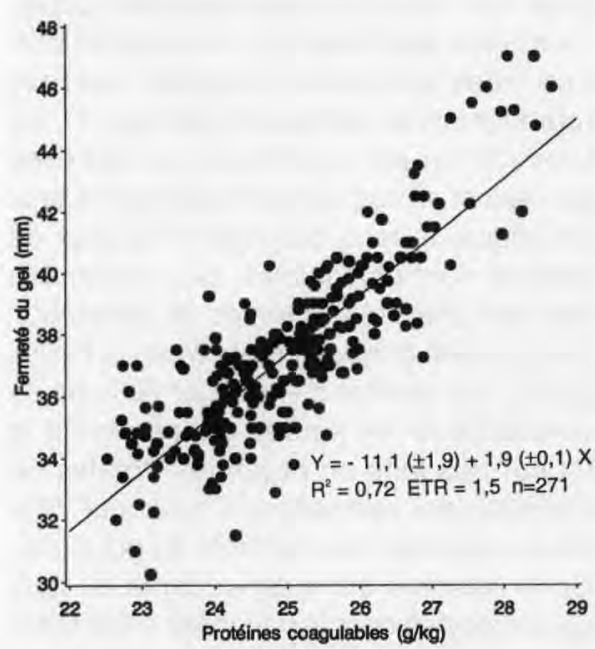

Fig 3. Relation entre le taux de protéines coagulables et la fermeté du gel des laits des troupeaux. Relationship between herd milk casein content and curd firmness.
La projection sur le premier plan factoriel des modalités des variables décrivant les facteurs de production des laits permet d'opposer, sur l'axe représentant la fermeté du gel les laits produits en été, qui proviennent des troupeaux dont le stade de lactation est le plus avancé et pour lesquels la proportion du variant $B$ de la caséine $\kappa$ est la plus élevée (du côté des gels les plus fermes) aux laits produits en hiver, par les troupeaux dont le stade de lactation est le moins avancé et pour lesquels la proportion du variant $B$ de la caséine $\kappa$ est la plus faible (fig 1). Les effets respectifs de ces 3 facteurs de variation qui, sur l'ensemble des laits analysés peuvent se confondre, ont été étudiés à partir de sous-ensembles laits différant par un seul de ces facteurs.

Stade physiologique moyen des troupeaux

Sous l'effet de l'augmentation du taux protéique lors de l'avancement du stade physiologique moyen des troupeaux, les gels les plus fermes ont été observés lorsque les troupeaux étaient en fin de lactation (fig 4). Cette relation a été linéaire entre le $4^{e}$ et le $7^{e}$ mois de lactation et a été semblable, que l'analyse soit réalisée à $\mathrm{pH}$ initial ou à $\mathrm{pH}$ ramené à 6,60 . L'augmentation rapide et la plus forte variabilité observée au-delà du $7^{\mathrm{e}}$ mois de lactation s'expliquent par le taux protéique des laits. Bien que la proportion des protéines coagulables dans les protéines totales ait été légèrement plus faible lorsque les troupeaux étaient au-delà du $6^{e}$ mois de lactation $(79,3 \%$ pour les stades de lactation inférieurs à 6 mois contre $78,8 \%$ en moyenne au-delà du $6^{\mathrm{e}}$ mois de lactation), on n'a pas noté d'effet propre des laits de fin de lactation et/ou de gestation sur le raffermissement des gels indépendamment de leur teneur en protéines coagulables (fig 4).

Le stade physiologique moyen des troupeaux n'a affecté le temps de gélification des laits des cuves qu'au-delà du $6^{\mathrm{e}}$ mois de 

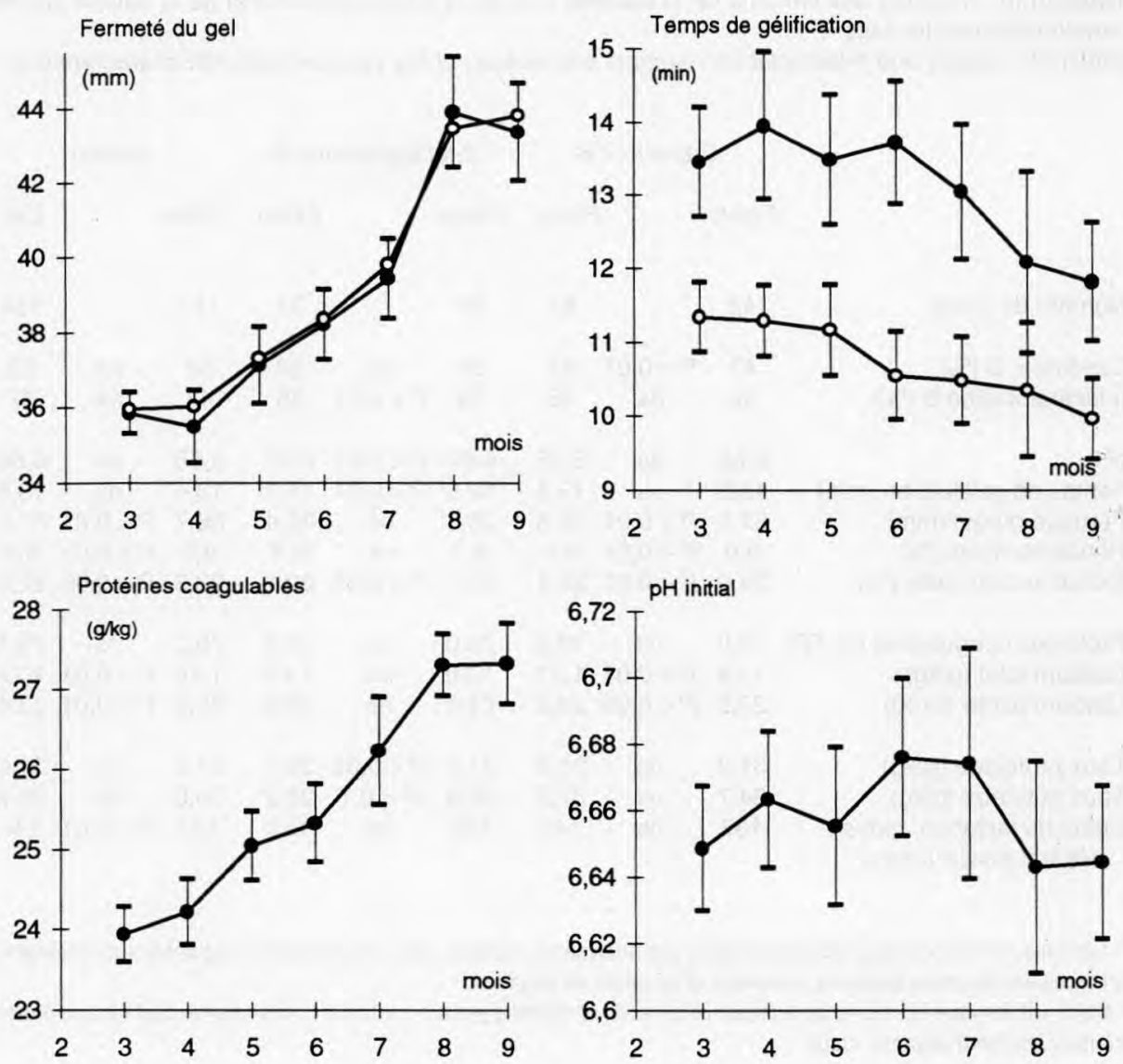

$\rightarrow$ mesure réalisée à pH initial —-mesure réalisée à pH 6,60

Fig 4. Influence du stade de lactation moyen du troupeau sur les caractéristiques des laits de troupeaux : fermeté du gel, temps de gélification, protéines coagulables, $\mathrm{pH}$ initial.

Effect of herd average lactation stage on herd milk characteristics: curd firmness, rennet clotting time, casein, initial $\mathrm{pH}$.

lactation (fig 4) où on a observé une diminution de $20 \%$ du temps de gélification mesuré à $\mathrm{pH}$ initial entre le $6^{\mathrm{e}}$ et le $9^{\mathrm{e}}$ mois de lactation. Le temps de gélification mesuré à $\mathrm{pH}$ ramené à 6,60 diminue également en fin de lactation, bien que de façon moins importante.
Variants génétiques de la caséine $\kappa$ et de la $\beta$-lactoglobuline

À même teneur en protéines coagulables (introduite en covariable dans l'analyse), comparativement à un sous-ensemble de laits pour lequel la proportion du variant $B$ de la caséine $\kappa$ dans le troupeau est faible 
Tableau III. Influence des variants de la caséine $\kappa$ et de la $\beta$-lactoglobuline et de la saison sur les caractéristiques des laits ${ }^{1}$.

Effect of $\kappa$-casein and $\beta$-lactoglobulin variants and season of the year on herd milk characteristics 1 .

\begin{tabular}{|c|c|c|c|c|c|c|c|c|c|}
\hline & \multicolumn{3}{|c|}{ Caséine $\kappa$ B } & \multicolumn{3}{|c|}{$\beta$-lactoglobuline $B$} & \multicolumn{3}{|c|}{ Saison } \\
\hline & Faible & & Élevé & Faible & & Élevé & Hiver & & Été \\
\hline Nombre de cuves & 42 & & 64 & 40 & & 37 & 117 & & 154 \\
\hline Caséine $\kappa \mathrm{B}(\%)$ & 43 & $P<0,01$ & 64 & 50 & ns & 52 & 52 & ns & 53 \\
\hline$\beta$-lactoglobuline B (\%) & 46 & ns & 48 & 34 & $P<0,01$ & 58 & 47 & ns & 47 \\
\hline $\mathrm{pH}$ & 6,66 & ns & 6,65 & 6,64 & $P<0,01$ & 6,67 & 6,65 & ns & 6,66 \\
\hline Temps de gélification (min) & 13,3 & ns & 13,3 & 12,6 & $P<0,01$ & 14,1 & 13,4 & ns & 13,6 \\
\hline Fermeté du gel $(\mathrm{mm})$ & 37,1 & $P<0,01$ & 38,3 & 36,3 & ns & 36,4 & 36,7 & $P<0,01$ & 37,9 \\
\hline Rendement sec $(\%)$ & 8,0 & $P<0,01$ & 8,4 & 8,3 & ns & 8,4 & 8,0 & $P<0,01$ & 8,2 \\
\hline Extrait sec du caillé (\%) & 23,0 & $P<0,01$ & 22,1 & 23,1 & $P<0,05$ & 22,1 & 23,3 & $P<0,05$ & 22,8 \\
\hline Protéines coagulables (\% TP) & 79,0 & ns & 79,2 & 79,0 & ns & 79,3 & 79,2 & ns & 79,1 \\
\hline Calcium total $(\mathrm{g} / \mathrm{kg})$ & 1,18 & $P<0,01$ & 1,21 & 1,19 & ns & 1,18 & 1,16 & $P<0,01$ & 1,22 \\
\hline Calcium/azote (x100) & 23,9 & $P<0,05$ & 524,6 & 24,4 & ns & 24,5 & 22,8 & $P<0,01$ & 23,6 \\
\hline Taux protéique $(\mathrm{g} / \mathrm{kg})$ & 31,3 & ns & 31,8 & 31,6 & $P<0,01$ & 30,5 & 31,5 & ns & 31,6 \\
\hline Taux butyreux ( $\mathrm{g} / \mathrm{kg}$ ) & 34,7 & ns & 37,2 & 36,8 & $P<0,1$ & 35,2 & 35,6 & ns & 35,7 \\
\hline $\begin{array}{l}\text { Stade de lactation moyen } \\
\text { des troupeaux (jours) }\end{array}$ & 137 & ns & 142 & 125 & ns & 123 & 127 & $P<0,01$ & 144 \\
\hline
\end{tabular}

1 Les valeurs mentionnées ont été corrigées par analyse de variance (taux de protéines coagulables en covariable) à l'exception des taux butyreux, protéique et du stade de lactation.

${ }^{1}$ Mean values were corrected by analysis of covariance (clotting protein content as covariate) except fat and protein content and herd lactation stage.

$(43 \%)$, les laits pour lesquels le variant B de la caséine $\kappa$ est plus fréquent $(64 \%)$ ont conduit à un gel plus ferme de $1,2 \mathrm{~mm}(P<$ $0,01)$, à des rendements secs supérieurs de $0,5 \%(P<0,05)$ et à un extrait sec des caillés plus faible de $0,9 \%(P<0,01)$ (tableau III). L'effet favorable du variant B de la caséine $\kappa$ ne peut être attribué en totalité à la teneur en calcium plus élevée de ces laits $(+0,03 \mathrm{~g} / \mathrm{kg}, P<0,01)$ dans la mesure où des effets similaires ont été observés lorsqu'on ne considère que les laits dont la teneur en calcium est voisine.

Le polymorphisme de $\beta$-lactoglobuline a eu un effet sur le temps de gélification : celui-ci a été significativement supérieur $(+13 \%, P<0,01)$ pour un sous-ensemble de laits caractérisés par une proportion du variant $B$ de la $\beta$-lactoglobuline élevée ( $58 \%$ ) comparativement à un sous-ensemble de laits caractérisés par une proportion du variant B de la $\beta$-lactoglobuline faible (34\%). Cet effet a été indépendant du stade de lactation des animaux, identique dans les 2 groupes de laits. Le polymorphisme de la $\beta$-lactoglobuline n'a pas eu d'effet sur la proportion de protéines coagulables dans les protéines totales. Le polymorphisme de la caséine $\kappa$ n'a pas affecté le temps de gélification. 


\section{Effet de la saison}

À même teneur en protéines coagulables, les laits provenant de la période estivale ont conduit à un gel plus ferme de $1,1 \mathrm{~mm}(P<$ 0,01 ) (fig 5) et à un rendement fromager plus élevé de $0,3 \%(P<0,01)$. Parallèlement, le taux de calcium et le rapport calcium colloïdal/protéines coagulables ont été significativement plus élevés en été qu'en hiver et on a pu vérifier que, à même teneur en protéines coagulables, le meilleur raffermissement des laits d'été a été d'autant plus marqué que le rapport calcium colloïdal/protéines coagulables était faible en hiver. C'est le cas notamment des laits d'hiver les plus riches en protéines, pour lesquels la faible teneur relative en calcium a pu constituer le facteur limitant le raffermissement du gel et l'obtention d'un rendement élevé. Le meilleur raffermissement des laits d'été ne s'explique cependant qu'en partie par leur teneur plus élevée en cal-

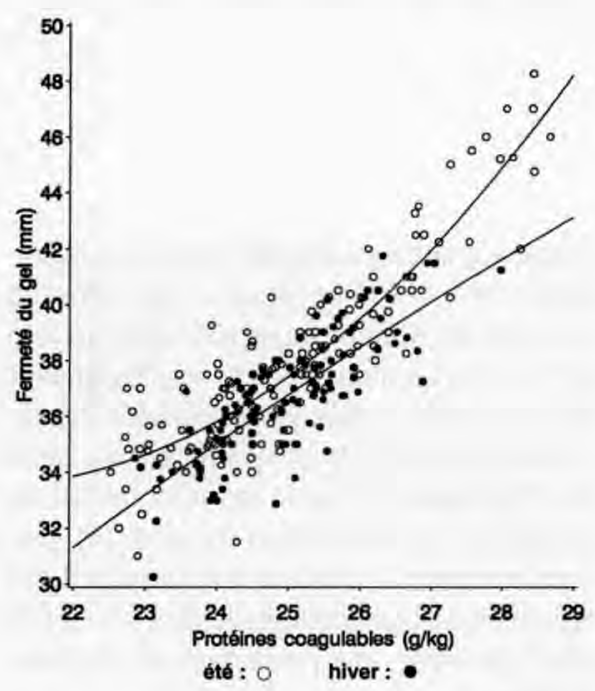

Fig 5. Relation entre le taux de protéines et la fermeté du gel des laits des troupeaux selon la saison $(n=271)$.

Relationship between herd milk casein content and curd firmness among season of the year. cium puisque lorsqu'on ne considère qu'un sous-ensemble de laits dont le rapport calcium/protéines coagulables est voisin, l'effet favorable de la période de pâturage reste significatif $(P<0,01)$.

\section{Étude sur les laits provenant d'animaux en milieu de lactation}

Compte tenu des fortes liaisons observées entre le stade physiologique des animaux et l'aptitude à la coagulation des laits, les effets des pratiques des éleveurs sur l'aptitude à la coagulation des laits ont été abordés à partir de sous-ensembles de laits pour lesquels le stade de lactation était compris entre le $110^{\circ}$ et le $160^{\mathrm{e}}$ jour. Sur cette faible plage de variation, le stade physiologique des troupeaux n'a pas affecté le temps de gélification (fig 4) et l'évolution de la fermeté du gel est restée limitée (fig 4).

Les laits conduisant à un coagulum ferme ayant été observés quel que soit leur comportement lors de la première phase de la coagulation, les facteurs de variation du temps de gélification et de la fermeté du gel on été étudiés séparément. Pour cela, à partir de la typologie des laits des cuves, on a regroupé d'une part les types de laits pour lesquels la gélification était rapide ou lente, et d'autre part les types de laits pour lesquels la fermeté du gel était élevée, moyenne ou faible (tableau IV).

\section{Temps de gélification}

Les gélifications lentes ou rapides ont été observées indifféremment en été ou en hiver (tableau V). En été, la fréquence des laits à gélification lente a été plus élevée sur l'alpage que sur le siège de l'exploitation $(P<0,05)$, mais le numéro de passage sur les parcelles, le stade de l'herbe, le type de pâturage ou les quantités d'aliments concentrés distribués n'ont pas été répartis différemment dans les 2 groupes de lait $(P>0,1)$ (tableau V). En revanche, les quantités de foin distribuées en plus du pâturage ont été 
Tableau IV. Caractéristiques des laits différant par la fermeté du gel ou par le temps de gélification (le stade de lactation moyen des troupeaux est compris entre 110 et 160 jours).

Herd milk characteristics differing from curd firmness or rennet clotting time (average herd lactation stage is between 110 and 160 days from calving)

\begin{tabular}{|c|c|c|c|c|c|c|c|c|c|}
\hline \multirow[b]{3}{*}{ Nombre de cuves } & \multicolumn{5}{|c|}{ Fermeté du gel } & \multicolumn{4}{|c|}{ Gélification } \\
\hline & \multirow{2}{*}{$\begin{array}{c}\text { Elevée } \\
35\end{array}$} & \multirow{2}{*}{$\begin{array}{c}\text { Moy } \\
56\end{array}$} & \multirow{2}{*}{$\begin{array}{c}\text { Faible } \\
\qquad 40\end{array}$} & \multicolumn{2}{|c|}{$\operatorname{ETR}^{(1)}$} & \multirow{2}{*}{$\begin{array}{c}\text { Rapide } \\
55\end{array}$} & \multirow{2}{*}{$\begin{array}{c}\text { Lente } \\
76\end{array}$} & \multicolumn{2}{|c|}{ ETR (1) } \\
\hline & & & & & & & & & \\
\hline \multicolumn{10}{|l|}{ Aptitude à la coagulation } \\
\hline $\begin{array}{l}\text { Fermeté du gel }(\mathrm{mm}) \\
\text { Temps de gélification (min) } \\
\text { pH } \\
\text { Rendement sec }(\%) \\
\text { Extrait sec du caillé }(\%)\end{array}$ & $\begin{array}{c}39,5 \\
13,1 \\
6,65 \\
8,7 \\
23,1\end{array}$ & $\begin{array}{c}37,3 \\
13,2 \\
6,65 \\
8,0 \\
23,5\end{array}$ & $\begin{array}{c}34,8 \\
14,4 \\
6,67 \\
7,7 \\
23,3\end{array}$ & $\begin{array}{c}1,0 \\
0,6 \\
0,04 \\
0,6 \\
1,8\end{array}$ & $\begin{array}{l}P<0,01 \\
P<0,01 \\
P<0,01 \\
P<0,01 \\
\quad \text { ns }\end{array}$ & $\begin{array}{c}37,8 \\
12,0 \\
6,63 \\
8,3 \\
23,6\end{array}$ & $\begin{array}{c}36,5 \\
14,5 \\
6,68 \\
8,0 \\
23,1\end{array}$ & $\begin{array}{c}1,9 \\
1,1 \\
0,04 \\
0,7 \\
1,8\end{array}$ & $\begin{array}{l}P<0,01 \\
P<0,01 \\
P<0,01 \\
P<0,01 \\
P<0,1\end{array}$ \\
\hline \multicolumn{10}{|l|}{ Composition chimique du lait } \\
\hline $\begin{array}{l}\text { Lait }(\mathrm{kg} / \mathrm{vache} / \mathrm{jour}) \\
\text { Taux butyreux }(\mathrm{g} / \mathrm{kg}) \\
\text { Taux protéique }(\mathrm{g} / \mathrm{kg}) \\
\text { Protéines coagulables (\%TP) } \\
\text { Calcium total }(\mathrm{g} / \mathrm{kg}) \\
\text { Calcium / Azote }(\mathrm{x} 100)\end{array}$ & $\begin{array}{c}9,1 \\
37,0 \\
32,4 \\
79,4 \\
1,21 \\
23,8\end{array}$ & $\begin{array}{c}8,9 \\
35,0 \\
31,6 \\
79,3 \\
1,19 \\
24,0\end{array}$ & $\begin{array}{c}8,6 \\
34,2 \\
30,6 \\
79,4 \\
1,16 \\
24,2\end{array}$ & $\begin{array}{l}1,6 \\
2,7 \\
0,8 \\
0,7 \\
0,05 \\
1,1\end{array}$ & $\begin{array}{c}\text { ns } \\
P<0,01 \\
P<0,01 \\
\text { ns } \\
P<0,01 \\
\text { ns }\end{array}$ & $\begin{array}{c}9,2 \\
36,3 \\
31,9 \\
79,4 \\
1,20 \\
23,9\end{array}$ & $\begin{array}{c}8,5 \\
34,5 \\
31,3 \\
79,3 \\
1,18 \\
24,1\end{array}$ & $\begin{array}{l}1,6 \\
2,7 \\
1,0 \\
0,7 \\
0,05 \\
1,1\end{array}$ & $\begin{array}{c}P<0,05 \\
P<0,01 \\
P<0,01 \\
\text { ns } \\
\text { ns } \\
\text { ns }\end{array}$ \\
\hline $\begin{array}{l}\text { Stade de lactation } \\
\text { des troupeaux (jours) }\end{array}$ & 138 & 136 & 130 & 12 & $P<0,1$ & 135 & 134 & 13 & ns \\
\hline
\end{tabular}

1 Écart type résiduel.

1 Residual standart deviation.

significativement plus élevées $(P<0,01)$ dans le groupe de lait à gélification rapide où de plus, les aliments concentrés étaient essentiellement des céréales, distribuées en plusieurs repas $(P<0,01)$. Par ailleurs, dans $73 \%$ des cas observés, les nuits passées à l'extérieur ont été associées aux laits à gélification lente alors que les nuits passées à l'intérieur ont été associées, dans $69 \%$ des cas, aux laits à gélification rapide.

En hiver, les laits à gélification rapide ont été associés en moyenne aux apports de foin et d'aliments concentrés plus importants $(P<0,01)$ et aux apports d'aliments concentrés les mieux adaptés au niveau de production des animaux. Par ailleurs, les gélifications rapides ont été plus fréquentes lorsque le lactosérum était distribué aux animaux $(P<0,01)$ et lorsque les aliments concentrés étaient apportés après le foin $(P<0,01)$. La nature des aliments concentrés apportés à tous les animaux a également été significativement différente dans les 2 groupes de laits; les concentrés de production du commerce (type VL18), distribués seuls à tous les animaux, ont été associés aux gélifications lentes $(P<0,01)$ par opposition aux mélanges de céréales aplaties.

\section{Fermeté du gel}

Le taux protéique des laits a été supérieur de $2 \mathrm{~g} / \mathrm{kg}$ dans le groupe de laits condui- 
Tableau V. Pratiques d'alimentation associées aux classes de lait différant par la fermeté du gel ou par le temps de gélification (le stade de lactation moyen des troupeaux est compris entre 110 et 160 jours). Feeding practices associated with herd milk groups differing in curd firmness or rennet clotting time (average herd lactational stage is between 110 and 160 days from calving).

\begin{tabular}{|c|c|c|c|c|c|c|c|}
\hline \multicolumn{5}{|c|}{ Fermeté du gel } & \multicolumn{3}{|c|}{ Gélification } \\
\hline Élevée & Moy & Faible & $E^{\prime} R^{1}$ & & Rapide & Lente & $E T R^{1}$ \\
\hline 35 & 56 & 40 & & & 55 & 76 & \\
\hline 39,5 & 37,3 & 34,8 & $1,0 F$ & $P<0,01$ & 37,8 & 36,5 & $1,9 \quad P<0,01$ \\
\hline 13,1 & 13,2 & 14,4 & $0,6 F$ & $P<0,01$ & 12,0 & 14,5 & $1,1 \quad P<0,01$ \\
\hline
\end{tabular}

$\begin{array}{lccccccccc}\text { Nombre de cuves } & 35 & 56 & 40 & & 55 & 76 & \\ \text { Fermeté du gel (mm) } & 39,5 & 37,3 & 34,8 & 1,0 & P<0,01 & 37,8 & 36,5 & 1,9 & P<0,01 \\ \text { Temps de gélification (min) } & 13,1 & 13,2 & 14,4 & 0,6 & P<0,01 & 12,0 & 14,5 & 1,1 & P<0,01 \\ \text { Répartition des types de lait par saison (effectifs) } & & & & & & \\ \quad \text { Hiver } & 20 & 28 & 22 & & \text { ns } & 31 & 39 & \text { ns } \\ \quad \text { Pâturage } & 15 & 28 & 18 & & & 24 & 37 & \end{array}$

Hiver

\begin{tabular}{|c|c|c|c|c|c|c|c|c|c|c|}
\hline Quantité de foin ( $\mathrm{kg} \mathrm{br}$ & rut/jour/vac & 14,9 & 14,3 & 12,8 & 1,6 & $P<0,01$ & 15,0 & 13,5 & 1,6 & $P<0,01$ \\
\hline $\begin{array}{l}\text { Concentré distribué p } \\
\text { de lait }(\mathrm{kg} / \mathrm{j})\end{array}$ & pour $25 \mathrm{~kg}$ & 6,4 & 6,1 & 5,8 & 2,1 & ns & 7,2 & 5,4 & 1,9 & $P<0,01$ \\
\hline $\begin{array}{l}\text { Ordre de distribution } \\
\text { (effectifs) }\end{array}$ & $\begin{array}{l}F \text { puis } C C \\
C C \text { puis } F\end{array}$ & $\begin{array}{c}9 \\
11\end{array}$ & $\begin{array}{l}18 \\
10\end{array}$ & $\begin{array}{l}12 \\
10\end{array}$ & & ns & $\begin{array}{l}21 \\
10\end{array}$ & $\begin{array}{l}10 \\
29\end{array}$ & & $P<0,01$ \\
\hline $\begin{array}{l}\text { Distribution } \\
\text { du sérum (effectifs) }\end{array}$ & $\begin{array}{l}\text { Non } \\
\text { Oui }\end{array}$ & $\begin{array}{c}3 \\
17\end{array}$ & $\begin{array}{l}12 \\
16\end{array}$ & $\begin{array}{c}14 \\
8\end{array}$ & & $P<0,01$ & $\begin{array}{c}5 \\
26\end{array}$ & $\begin{array}{l}24 \\
15\end{array}$ & & $P<0,01$ \\
\hline $\begin{array}{l}\text { Nombre de repas } \\
\text { (effectifs) }\end{array}$ & $\begin{array}{c}2 \\
3 \text { ou plus }\end{array}$ & $\begin{array}{c}9 \\
11\end{array}$ & $\begin{array}{c}19 \\
9\end{array}$ & $\begin{array}{c}22 \\
0\end{array}$ & & $P<0,01$ & $\begin{array}{l}15 \\
16\end{array}$ & $\begin{array}{c}35 \\
4\end{array}$ & & $P<0,01$ \\
\hline
\end{tabular}

Été

Numéro de passage sur les parcelles (effectifs)

\begin{tabular}{|c|c|c|c|c|c|c|c|c|c|c|}
\hline $1^{\text {er }}$ pass & ge & 8 & 15 & 3 & & $P<0,05$ & 13 & 13 & & ns \\
\hline Repous & es alpage & 5 & 10 & 6 & & & 6 & 15 & & \\
\hline Repous & es bas & 2 & 3 & 9 & & & 5 & 9 & & \\
\hline l'herbe & urs) ${ }^{2}$ & 30 & 30 & 45 & 18 & $P<0,05$ & 31 & 37 & 19 & ns \\
\hline e foin $(\mathrm{kc}$ & orut/vache/jour) & 3,3 & 1,9 & 1,9 & 2,6 & ns & 3,5 & 1,5 & 2,5 & $P<0,01$ \\
\hline $\begin{array}{l}\text { distribu } \\
\mathrm{kg} \text { de la }\end{array}$ & $(\mathrm{kg} / \mathrm{j})$ & 3,7 & 3,6 & 3,4 & 1,8 & ns & 4,0 & 3,3 & 1,7 & ns \\
\hline le repas & $\begin{array}{l}1 \\
2\end{array}$ & $\begin{array}{l}8 \\
6\end{array}$ & $\begin{array}{c}23 \\
5\end{array}$ & $\begin{array}{c}13 \\
5\end{array}$ & ns & ns & $\begin{array}{l}12 \\
12\end{array}$ & $\begin{array}{c}33 \\
4\end{array}$ & & $P<0,01$ \\
\hline jour seu & ment (effectifs) & 5 & 5 & 3 & & ns & 9 & 4 & & $P<0,01$ \\
\hline jour $+s$ & & 2 & 3 & 2 & & & 4 & 3 & & \\
\hline jour $+n$ & & 8 & 20 & 13 & & & 11 & 30 & & \\
\hline
\end{tabular}

\footnotetext{
1 Écart type résiduel. Residual standard deviation.

2 Le stade de l'herbe correspond au stade du dactyle par rapport au début de la montaison lors du premier passage et au temps de repousse entre 2 passages lors des passages ultérieurs sur les parcelles.

Grass phenological stage is number of days since start steam elongation of cox-foot during first cut and cut frequency for next cuts.
} 
sant à un gel ferme comparativement au groupe de laits conduisant à un gel mou $(P<0,01)$. Au cours de la période de pâturage, les gels les plus fermes ont été très caractéristiques de l'alpage $(P<0,01)$, et plus particulièrement du premier passage sur les parcelles $(P<0,05)$ lorsque le stade de l'herbe était peu avancé $(P<0,01)$ (tableau V). À l'opposé, les laits conduisant à des gels mous ont été produits indifféremment sur l'alpage ou sur le siège des exploitations mais ils proviennent préférentiellement des pâturages sur repousses lorsque la durée entre 2 passages était la plus longue $(P<0,05)$. En moyenne, la complémentation du pâturage en fourrages secs et/ou en aliments concentrés a été plus élevée pour les gels fermes ( $7 \mathrm{~kg} / \mathrm{vache} / \mathrm{j})$ que pour les gels mous $(5,3 \mathrm{~kg} / \mathrm{vache} / \mathrm{j})$. Le type de pelouse pâturée n'a pas eu d'effet significatif sur la fermeté du gel $(P>0,1)$ et on n'a pas observé d'interaction avec le stade de l'herbe. Par ailleurs, les journées pluvieuses ont été associées aux fermetés du gel moyennes ou élevées $(P<0,05)$. Les journées pluvieuses ont cependant été associées à des complémentations en fourrages secs plus importantes et à une herbe dont le stade a été plus précoce.

En hiver, comparativement aux laits conduisant à un gel ferme, les laits conduisant à un gel mou ont été associés à des apports de foin et d'aliments concentrés plus faibles respectivement de $2,1 \mathrm{~kg}$ de foin/vache/j $(P<0,05)$ et de $1,2 \mathrm{~kg}$ de concentré/vache/j. Par ailleurs, dans le groupe de laits conduisant à un gel mou, les apports d'aliments concentrés ont été moins bien adaptés aux besoins des animaux $(P<0,01)$, la proportion de foin de qualité moyenne a été plus élevée, bien que de manière non significative $(26 \%$ contre $7 \%, P>0,1)$, et le sérum a été distribué plus rarement que dans le groupe de laits conduisant aux gels les plus fermes $(P<0,01)$. En revanche, la nature des foins et des aliments concentrés, et leurs moda- lités d'apport ont été voisines dans les 3 groupes de laits.

\section{DISCUSSION}

Cette étude a permis dans un premier temps de bien distinguer la durée de la gélification et la fermeté du gel (mesurée après un temps de raffermissement égal au temps de gélification), qui ont été très faiblement corrélées. Cette absence de liaison est étonnante dans la mesure où de nombreux auteurs ont mis en évidence que les laits dont la gélification est lente forment généralement un gel mal structuré (Mocquot et al, 1954 ; Grandison et al, $1984 \mathrm{~b}$ et $1985 \mathrm{~b}$; Remeuf et al, 1991 ; Nuyts-Petit, 1991). Elle peut cependant illustrer le fait que les mécanismes de ces 2 phases sont de nature différente (Brulé et Lenoir, 1987 ; Brulé, 1991) et qu'ils ne dépendent pas des mêmes facteurs (Remeuf et al, 1991). Par ailleurs, l'absence de liaison entre la fermeté du gel et le temps de gélification peut également s'expliquer par la technique de mesure de la fermeté du gel que nous avons choisie (mesurée après un temps relatif au temps de gélification). La fermeté mesurée $30 \mathrm{~min}$ après l'introduction de la présure a en effet été fortement corrélée négativement au temps de gélification $\left(R^{2}=0,77\right)$. Ces observations confirment que la signification de la fermeté du gel dépend fortement du moment où est réalisée la mesure (Grandison et Ford, 1986).

Comme cela a été mis en évidence par de nombreux auteurs, le temps de gélífication a été d'autant plus court que le $\mathrm{pH}$ initial du lait était plus bas (O'Keeffe, 1984 ; Grandison et al, 1985b ; Delacroix, 1985 ; Remeuf et al, 1991). Cela s'explique, d'une part, par une augmentation de l'activité de la chymosine (dont le pH optimum est voisin de 5,5 ) et d'autre part par une diminution de la stabilité des micelles de caséines (Shalabi et Fox, 1982), due à la neutralisa- 
tion de leurs charges et à la solubilisation du calcium colloïdal (Holt et Muir, 1978; Le Graet et Brulé, 1993). Les causes de variation du $\mathrm{pH}$ du lait propres à l'animal sont cependant très mal connues (Anderson, 1992), à l'exception de l'effet de l'état sanitaire de la mamelle qui, lorsqu'il est défectueux entraîne une forte augmentation du pH (Grandison et Ford, 1986 ; Politis et NgKwai-Hang, 1988).

Le stade physiologique moyen des troupeaux a affecté le temps de gélification des laits à partir du $7^{e}$ mois de lactation. $\mathrm{Ce}$ résultat est en accord avec les principaux travaux antérieurs réalisés dans cette région (ITG, 1981 ; Coulon et al, 1988) ou dans d'autres conditions de milieu (Auriol, 1961; Mariani et al, 1982). Cette diminution du temps de gélification ne s'explique pas uniquement par la diminution du $\mathrm{pH}$ initial du lait puisqu'une diminution du temps de gélification est également observée lorsque la mesure est réalisée à $\mathrm{pH}$ ramené à 6,60 . Cette évolution au cours de la lactation a été rapprochée par certains auteurs de l'évolution inverse du rapport calcium/azote (Auriol, 1961). La corrélation entre ces 2 caractéristiques du lait est cependant généralement faible (ITG, 1981) et n'a pas été observée dans cette étude. D'autres auteurs ont en revanche montré une augmentation du temps de gélification lors de l'avancement du stade de lactation des animaux (Okigbo et al, 1985 ; Lucey et Fox, 1992 : White et Davies, 1958). Lucey et Fox (1992) ont suggéré que le temps de gélification des laits de fin de lactation pouvait dépendre de la conduite alimentaire des animaux. Les pratiques d'alimentation favorables au temps de gélification vont globalement dans le sens d'apports nutritifs accrus. Ces pratiques ont été à l'origine de plus fortes teneurs en protéines qui, du fait de leur pouvoir tampon, pourraient jouer un rôle dans le contrôle du pH du lait (Anderson, 1992). Les liaisons entre le $\mathrm{pH}$ du lait et son taux protéique sont cependant souvent très lâches (Storry et Ford, 1982) et un enrichissement du lait en protéines ne provoque pas de modification notable de son $\mathrm{pH}$ (Dalgleish, 1980) bien que généralement il soit associé à une légère augmentation du temps de gélification qui s'explique par une diminution du rapport enzyme/substrat (Brulé, 1991). Par ailleurs, les travaux réalisés en situation expérimentale (Vertès et al, 1989 ; Macheboeuf et al, 1993) ou en fermes (Martin et Coulon, 1991) n'ont jamais mis en évidence un effet du niveau des apports énergétiques sur la durée de la première phase de la coagulation. II est donc peu probable que les différences observées soient imputables directement au niveau d'alimentation des troupeaux. Enfin, en dehors des changements d'alimentation liés à la mise à l'herbe qui s'accompagnent également de changements d'environnement (Grandison et al, 1984a ; Mariani et al, 1985 ; Vertès et al, 1989 ; Macheboeuf et al, 1993) la nature des aliments semble avoir peu d'effets sur le temps de gélification (Grandison et al, 1985a ; Vertès et al, 1989 ; Coulon et Garel, 1993). Les associations entre l'alimentation des animaux et le temps de gélification des laits restent donc difficiles à interpréter et il est possible qu'elles cachent des facteurs non pris en compte dans cette étude qui pourraient être d'ordre génétique ou liés à l'environnement des animaux.

Cette étude a confirmé, sur des laits de troupeaux, l'influence prépondérante du taux de protéines coagulables et donc de caséines sur la fermeté du gel (Storry et Ford, 1982 ; Storry et al, 1983 ; Grandison et $a l, 1984 a$ et b et $1985 b$; Vertès et al, 1989 ; Remeuf et al, 1991). Cette influence s'explique par la nature même du gel, constitué d'un réseau tridimensionnel de micelles de paracaséines emprisonnant les autres constituants du lait. Lorsque le taux de caséines augmente, le réseau devient plus dense, le nombre de liaisons intermoléculaires est plus important, ce qui a pour effet 
d'améliorer la consistance du coagulum (Brulé, 1991).

Cet effet explique l'évolution de la fermeté du gel avec le stade physiologique, puisque le taux protéique augmente pratiquement de manière linéaire à partir du deuxième mois de lactation (Rémond, 1987 ; Schultz et al, 1990). Les rares données de la bibliographie disponibles sur ce sujet n'avaient cependant pas mis en évidence un effet aussi marque du stade de lactation des animaux (Mariani et al, 1982 ; Bonato et al, 1987).

L'effet du taux protéique sur la fermeté du gel explique aussi par l'effet favorable de l'ensemble des pratiques d'alimentation conduisant à un niveau d'apport nutritif élevé. Comme cela a déjà été observé en situation expérimentale (Vertès et al, 1989 ; Macheboeut et al, 1993), l'essentiel de cet effet s'explique par l'augmentation de la teneur en protéines du lait lors d'un accroissement des apports énergétiques, largement mis en évidence par ailleurs (Sutton, 1989; Coulon et Rémond, 1991). Bien que la nature essentiellement qualitative de ces observations ne permette pas de quantifier les apports énergétiques, des pratiques d'alimentation de cette nature ont fréquemment été associées en exploitations à des taux protéiques élevés (Coulon, 1991). De plus, ces pratiques d'alimentation favorables au taux protéique et à la fermeté du gel ont été associées à des animaux en meilleur état corporel, ce qui rend bien compte du niveau d'alimentation des troupeaux.

En dépit de la forte liaison existant entre la teneur des laits en protéines coagulables et la fermeté du gel, on a cependant observé, comme Storry et al (1983), que certains laits pouvaient dévier considérablement de cette relation. La variabilité résiduelle n'a pas été liée au taux de leucocytes (globalement très faible) comme l'ont mis en évidence Grandison et Ford (1986). Elle a été liée en premier lieu au polymorphisme des protéines du lait. En particulier, comme cela a déjà été mis en évidence par de nombreux auteurs sur des laits individuels (Schaar, 1984 ; Marziali et Ng-KwaiHang, 1986 a et b ; Grosclaude, 1988 ; Rahali et Ménard, 1991; Macheboeuf et al, 1993 ; Delacroix-Buchet et al, 1993), le variant $B$ de la caséine $\kappa$ a eu un effet favorable sur la fermeté du gel des laits des troupeaux. Un écart de fréquence allélique de l'ordre de $20 \%$ seulement a conduit à une différence de fermeté du gel équivalente à celle que peut provoquer une différence de $1 \mathrm{~g} / \mathrm{kg}$ de taux protéique. L'accroissement de la fermeté du gel observé avec le variant $B$ ne peut être attribué à la teneur en protéines coagulables, très voisine dans les 2 groupes de laits. II s'agit donc d'un effet propre qui pourrait être lié à la plus grande richesse en caséine $\kappa$ du variant $B$ de la caséine $\kappa$ (McLean et al, 1984) et à des micelles plus régulières et de plus petite taille (Morini et al, 1975) qui fusionnent plus étroitement et conduisent à un gel plus ferme (Niki et Arima, 1984 ; Remeuf et al, 1991). Cet effet du polymorphisme de la caséine $\kappa$, mis en évidence sur des laits de troupeaux est donc particulièrement important dans la mesure où tous les animaux étaient de même race et que les différences de fréquence allélique restaient limitées.

Cette étude a également montré un effet favorable de la période de pâturage sur la fermeté du gel et sur les rendements fromagers estimés par centrifugation. Pour un même taux protéique, l'écart observé entre l'été et l'hiver correspond à une différence de fermeté provoquée par $1 \mathrm{~g} / \mathrm{kg}$ de taux protéique. Ces résultats obtenus sur la fermeté du gel vont dans le même sens que les observations de Chapman et Burnett (1972) et Chapman (1974). Cet effet de la saison est à rapprocher des améliorations considérables de la fermeté du gel fréquemment observées lors de la mise à l'herbe et qui ne semblent pas pouvoir s'expliquer par la seule augmentation concomitante de la teneur des laits en protéines (Grandison et 
al, 1984a ; Vertès et al, 1989 ; Macheboeuf et al, 1993). Cet effet s'explique en partie par la plus forte teneur en calcium et par le rapport calcium/azote plus élevé des laits d'été. L'influence de la teneur en calcium sur la fermeté du gel est depuis longtemps reconnue (Grandison et al, 1984b ; Okigbo et al, 1985 ; Remeuf et al, 1991). On sait également que l'addition de chlorure de calcium est une pratique courante en fromagerie qui permet d'obtenir des caillés mieux structurés (Kowalchyk et Olson, 1979) ; cette influence résulte à la fois de l'augmentation en calcium ionique, de l'abaissement du $\mathrm{pH}$ et de l'augmentation du calcium micellaire, qui est un facteur déterminant de la formation du coagulum (Pyne et McGann, 1962). Cette étude a d'ailleurs permis de montrer que l'effet favorable du pâturage sur la fermeté du gel et sur les rendements de laboratoire n'était sensible que lorsque la minéralisation calcique des protéines coagulables des laits d'hiver était inférieure à une valeur voisine de $3,10 \mathrm{~g}$ de calcium colloïdal pour $100 \mathrm{~g}$ de protéines coagulables. Cette valeur semble constituer un seuil en dessous duquel le raffermissement du gel n'est plus limité par le taux de caséine mais par sa teneur relative en calcium.

En revanche, l'évolution saisonnière du taux de calcium ou de la minéralisation calcique des protéines coagulables que nous avons observée est plus difficile à interpréter. Si nos résultats confirment les augmentations observées par certains auteurs lors de la mise à l'herbe (Martin et Coulon, 1991 ; Hauwuy et al, 1992 ; Macheboeuf et al, 1993), ils ne vont pas dans le sens de la plupart des auteurs qui observent que les teneurs en calcium du lait diminuent à la mise à I'herbe (Grandison et al, 1984a ; Delacroix, 1985 ; Vertès et al, 1989) et sont minimales en été (Auriol et Mocquot, 1962 ; Guéguen, 1971) en raison de leur variation en sens inverse de la durée du jour. Les différences saisonnières de teneur des laits en calcium ne permettent cependant d'expli- quer qu'en partie, l'effet propre de la saison sur la fermeté du gel puisque des différences subsistent entre l'été et l'hiver lorsqu'on ne considère que les laits dont la minéralisation calcique est voisine. Cet effet de la saison s'explique peut-être par des modifications saisonnières des différentes fractions caséïques parfois mises en évidence (Macheboeuf et al, 1993) ou plus certainement par des micelles de plus petite taille observées en été (Holt et Muir, 1978). Généralement, les variations de taille des micelles ne sont cependant pas indépendantes de la teneur des laits en calcium (Green, 1982).

En pratique, cette étude montre donc que même sur des laits de mélange, pour un même taux de protéines coagulables, il peut subsister d'importants écarts de fermeté du gel. On a par exemple observé, pour un même taux protéique, une différence de fermeté du gel de $10 \%$ entre le lait d'été du producteur 5 et le lait d'hiver du producteur 4 (fig 6). Une telle différence de fermeté du

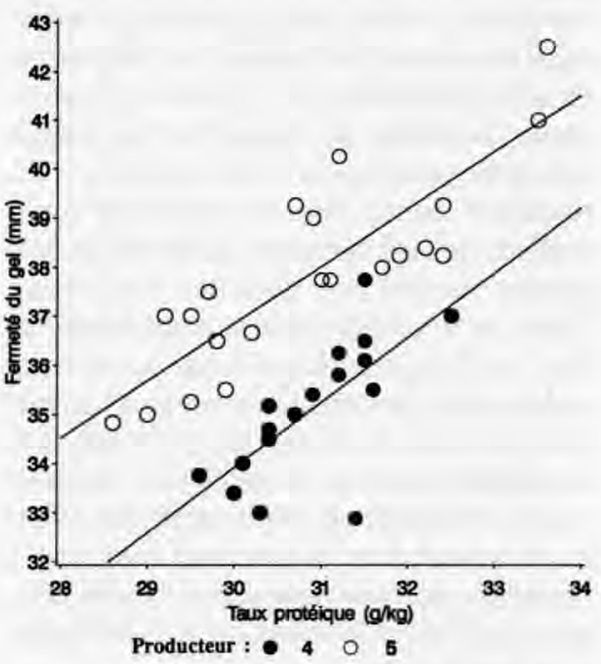

Fig 6. Relation entre le taux protéique et la fermeté du gel, observée chez 2 producteurs, en été pour le producteur 5 et en hiver pour le producteur 4.

Relationship between herd milk protein content and curd firmness observed in 2 dairy farms, in summer for farm 5 and in winter for farm 4. 
gel, qui équivaut à un écart de $2,5 \mathrm{~g} / \mathrm{kg}$ de taux protéique, observée entre des troupeaux constitués d'un seul génotype et conduits de façon comparable peut laisser penser que des différences beaucoup plus importantes existent entre des troupeaux de génotypes différents et conduits dans des conditions de milieu plus hétérogènes.

\section{CONCLUSION}

Cette étude a permis de confirmer et de hiérarchiser à l'échelle du troupeau la plupart des facteurs de variation de l'aptitude à la coagulation des laits mis en évidence en conditions expérimentales sur des laits individuels. Ainsi, à l'échelle de l'exploitation, les facteurs de variation de la fermeté du gel sont maintenant bien connus et les leviers d'action dont disposent les éleveurs pour améliorer ce critère de l'aptitude à la coagulation sont bien identifiés. À court terme, il sont essentiellement d'ordre alimentaire (amélioration du niveau énergétique des rations) et à moyen ou long terme, ils sont essentiellement d'ordre physiologique (périodes de vêlages) ou génétique (variants génétiques de la caséine $\kappa$ ). En revanche, contrairement à celles de la fermeté du gel, les variations du temps de gélification restent plus délicates à analyser. Elles font intervenir dans la plupart des cas des modifications du $\mathrm{pH}$ initial du lait mais ses facteurs de variation propres à l'animal sont très mal connus (Anderson, 1992). Si la variabilité du temps de gélification du lait a moins d'importance en fromagerie où le $\mathrm{pH}$ du lait peut être facilement maîtrisé à l'emprésurage, elle reste préoccupante chez les producteurs fermiers qui doivent généralement la subir.

\section{REMERCIEMENTS}

Ce travail n'aurait pu être mené à bien sans la collaboration des producteurs de reblochon fer- mier de la vallée de Thönes chez qui cette étude a èté réalisée (G Ballanfat, A Ménégon, S Suize et JP Tissot-Rosset et les membres du GAEC Bellachat et du GAEC de la Bottière) et sans le concours de E Combaz, JM Barnabé, Y BurnetMerlin, B Mathieu et S Romand du Service technique du Syndicat interprofessionnel du reblochon, de A Déchanet et G Jolivot du Syndicat de contrôle laitier de la Haute-Savoie, de I Philippot et X Folliet de la Chambre d'agriculture de la Haute-Savoie et F Farges de la Coopérative des producteurs de reblochon fermier qui ont largement contribué aussi bien à la mise en place qu'à la réalisation quotidienne de ce travail. Nous tenons à les remercier pour leur active collaboration. Nous remercions également MF Mahé de I'INRA de Jouy-en-Josas qui a réalisé la caractérisation des variants génétiques des protéines du lait et JF Ciclet de l'ENILV de La Roche-surForon pour la mise à disposition de son laboratoire. Nous remercions enfin JF Chamba de PITG de La Roche-sur-Foron qui a assuré une relecture critique de ce document.

\section{RÉFÉRENCES}

AFNOR (1971) Lait. Détermination de la teneur en matière grasse. Méthode acidobutyrométrique. Norme NF VO04-210

Aleandri R, Buttazzoni LG, Schneider JC, Caroli A, Davoli $R$ (1990) The effect of milk protein polymorphisms on milk components and cheese-producing ability. J Dairy Sci 73, 241-255

Anderson RR (1992) Changes in milk pH and bicarbonate during 20 days of lactation in the guinea pig. J Dairy Sci 75, 105-110

Auriol P (1961) Quelques facteurs de variation du temps de coagulation des laits individuels de vache. Ann Biol Anim Biochim Biophys 1, 152-162

Auriol P, Mocquot G (1962) Quelques facteurs de variation de la teneur en calcium des laits de vache. J Dainy Res 29, 181-189

Bonato P, Disegna L, Spolaor D, Zanatta P (1987) Effetto di stagione, stadio di lattazione, tecnica di alimentazione sulle caratteristiche chimiche e reologiche dei latti. Sci Tec Latt Casearia 4, 344-375

Bornard A (1992) Typologie de la végétation des alpages laitiers des Alpes du Nord. Fiches Techniques. CEMAGREF-INERM de Grenoble, GIS Alpes du Nord

Brulè G (1991) Caractéristiques physico-chimiques des protéines du lait. Aptitude à la coagulation. In : Qualité des laits à la production et aptitudes fromagères, Rennes, 23-24 janvier 
Brulé G, Lenoir J (1987) La coagulation du lait. In : Le fromage (Eck A, ed) Lavoisier, Paris

Chapman HR, Burnett $J$ (1972) Seasonal changes in the physical properties of milk for cheesemaking. Dairy Ind 37, 207-211

Chapman HR (1974) The effect the chemical quality of milk has on cheese quality. Dairy Ind 39, 329-334

Coulon JB (1991) Facteurs de variations du taux protéique du lait de vache en exploitation. Réflexions à partir de résultats d'enquētes. INRA Prod Anim 4, 303-309

Coulon JB, Rémond B (1991) Réponses de la production et de la composition du lait de vache aux variations d'apports nutritifs. INRA Prod Anim 4, 49-56

Coulon JB, Garel JP (1993) A note on the effect of forage type on yied, chemical composition and clotting properties of milk. Anim Prod 57, 495-499

Coulon JB, Roybin D, Congy E, Garret A (1988) Composition chimique et temps de coagulation du lait de vache: facteurs de variations dans les exploitations du Pays de Thônes. INRA Prod Anim 1, 253-263

Dalgleish DG (1980) Effet of milk concentration on the rennet coagulation time J Dairy Res 47, 231-235

Delacroix A (1985) Étude des variations individuelles de la composition chimique (fractions azotées et minérales) et de quelques caractéristiques technologiques des laits de vache en fonction de l'alimentation. Thèse, ENSA Rennes-Université de Rennes I

Delacroix-Buchet A, Lefier D, Nuyts-Petit V (1993) Polymorphisme de la caséine $\kappa$ dans trois races bovines françaises et aptitude à la coagulation. Lait 73, 61-72

Grandison AS, Ford GD (1986) Effects of variations in somatic cell count on the rennet coagulation properties of milk and on the yield, composition and quality of Cheddar cheese. J Dairy Res 53, 645-655

Grandison AS, Ford GD, Owen AJ, Millard D (1984a) Chemical composition and coagulating properties of renneted Friesian milk during the transition from winter rations to spring grazing. J Dairy Res $51,69-78$

Grandison AS, Ford GD, Millard D, Owen AJ (1984b) Chemical composition and coagulating properties of renneted milks from cows during early lactation. $J$ Dairy Res 51,407-416

Grandison AS, Manning DJ, Thomson DJ, Anderson M (1985a) Chemical composition, rennet coagulation properties and flavor of milks from cows grazing ryegrass or white clover. J Dairy Res 52, 33-39

Grandison AS, Anderson M, Ford GD, Newell L (1985b) Interrelationships between the diet fed to cows, composition and properties of milk and composition and quality of Cheshire cheese from farmhouse manufacturers. J Dairy Res 52, 587-593

Green ML (1982) Effect on the composition and properties of casein micelles of interaction whith ionic materials. J Dairy Res 49, 87-98
Grosclaude F (1988) Le polymorphisme génétique des principales lactoproteines bovines Relations avec la quantité, la composition et les aptitudes fromagères du lait. INRA Prod Anim 1, 5-17

Guéguen L (1971) La composition minérale du lait et son adaptation aux besoins du jeune. Ann Nutr Anim 25. A335-A381

Hauwuy A, Paradis J, Coulon JB (1992) Complémentation énergétique de rations à base de foin pour les vaches laitières. INRA Prod Anim 5, 339-346

Holt C, Muir DD (1978) Natural variations in the ave. rage size of bovine casein micelles. II. Milks samples from creamery bulk silos in south west Scotland. J Dairy Res 45, 347-353

Hurtaud C, Vérité R, Rulquin H (1991) Détermination de l'aptitude des laits á la transformation fromagère. Intérêts et limites des tests de laboratoire. In : Qualité des laits à la production et aptitude fromagère, Rennes, 23-24 janvier

ITG, EDE de Haute-Savoie (1981) Étude du temps de coagulation

Kowalchyk AW, Olson NF (1979) Milk clotting and curd firmness as affected by type of milk clotting enzyme, calcium chloride concentration, and season of year. J Dairy Sci 62,1233-1237

Lawrence RC, Heap HA, Gilles J (1984) A controlled approach to cheese technology. J Dairy Sci67, 16321645

Le Graet Y, Brulé G (1993) Les équilibres minéraux du lait : influence du $\mathrm{pH}$ et de la force ionique. Lait 73 , 51-60

Lucey JA, Fox PF (1992) Rennet coagulating properties of late-lactation milk : Effect of $\mathrm{pH}$ adjustement, addition of $\mathrm{CaCl}_{2}$, variation in rennet level and blending with mid-lactation milk. Irish J Agric Food Res 31, 173-184

McLean DM, Graham ERB, Ponzoni RW, McKenzie HA (1984) Effect of milk protein genetic variants on milk yield and composition. J Dairy Res 51, 531-546

McMahon DJ, Brown RJ (1982) Evaluation of Formagraph for comparing rennet solutions. J Dairy Sci $65,1639-1642$

Macheboeuf D, Coulon JB, D'Hour P (1993) Effect of breed, protein genetic variants and feeding on cow's milk coagulation properties. J Dairy Res $60,43-54$

Mariani P, Pecorari M, Fossa E (1982) Le caratteristiche di coagulazione del latte in rapporto allo stadio della lattazione ed ai livelli di produzione. Sci Tec Latt Casearia 33, 409-425

Mariani P, Brizzi S, Pecorari M, Fossa E (1985) Le caratteristiche acidometriche e di coagulazione del latte in rapporto al cambio primaverile di alimentazione. Sci Tec Latt Casearia 36, 143-159

Martin B, Coulon JB (1991) Aptitude fromagère du lait de vache : influence de l'alimentation. Étude réalisée 
dans 6 exploitations du Pays de Thônes (HauteSavoie). INRA Prod Anim 4, 209-217

Martin B, Coulon JB (1995) Facteurs de production du lait et caractéristiques des fromages. II. Influence des caractéristiques des laits de troupeaux et des pratiques fromagères sur les caractéristiques du Reblochon de Savoie fermier. Lait (sous presse)

Marziali AS, Ng-Kwai-Hang KF (1986a) Relationships between milk protein polymorphisms and cheese yielding capacity. J Dairy Sci 69, 1193-1201

Marziali AS, Ng-Kwai-Hang KF (1986b) Effect of milk composition and genetics polymorphism on cheese composition. J Dairy Sci 69, 2533-2542

Michel MC (1971) Analyse quantitative de quelques substances azotées et glucidiques en milieu biologique. Essai de rationalisation. Thèse, Université ClermontFerrand

Mocquot G, Alais C, Chevalier R (1954) Étude sur les défauts de coagulation du lait par la présure. Ann Technol 1, 1-44

Morini D, Losi G, Castagnetti G, Benevelli M, Resmini P. Volonterio $G$ (1975) The influence of genetic variants of $\kappa$ casein on the size of casein micelles. Sci Tec Latt Casearia 26, 437-444

Morini D, Losi G, Castagnetti G, Mariani P (1979) Prove di caseificazione con latte caratterizzato dalle varianti A e B della kappa caseina : rilievi sul formaggio stagionato. Sci Tec Latt Casearia 30, 243-262

Ng-Kwai-Hang KF, Hayes JF, Moxley JE, Monardes HG (1987) Variations in milk protein concentrations associated with genetic polymorphism and environmental factors. J Dairy Sci 70, 563-570

Niki R, Arima S (1984) Effects of size of casein micelle on firmness of rennet curd. Jpn J Zootech Sci 6, 409-415

Nuyts-Petit V (1991) Influence des variants génétiques des caséines bovines sur l'aptitude fromagère du lait de vaches de races traditionelles. Thèse, Université Compiègne

O'Keeffe AM (1984) Seasonal and lactational influences on moisture content of Cheddar cheese. Irish J Food Sci Technol 8, 27-37

Okigbo LM, Richardson GH, Brown RJ, Ernstrom CA (1985) Variations in coagulating properties of milk from individual cows. J Dairy Sci $68,822-828$

Politis I, Ng-Kwai-Hang KF (1988) Effect of somatic cell counts and milk composition on the coagulating properties of milk. J Dairy Sci 71, 1740-1746
Pyne GT, McGann CA (1962) The influence of the colloidal phosphate of milk on the rennet coagulation. CR XVle Congr Int Lait Copenhague, B 611

Rahali V, Ménard JL (1991) Influence des variants génétiques de la $\beta$-lactoglobuline et de la $\kappa$-caséine sur la composition du lait et son aptitude fromagère. Lait 71, 275-297

Remeuf F, Cossin V, Dervin C, Lenoir J, Tomassone R (1991) Relations entre les paramètres physico-chimiques des laits et leur aptitude fromagère. Lait 71 , $397-421$

Rémond B (1987) Influence du stade de lactation et de l'âge sur la composition chimique du lait. In : Le lait, matière première de l'industrie laitière. (INRA CEPIL), Paris, 151-159

SAS (1987) SAS User's Guide : Statistics Cary, NC:SAS Institute

Schaar J (1984) Effets of $\kappa$-casein genetic variants and lactation number on the renneting properties of individual milks. J Dairy Res 51, 397-406

Schutz MM, Hansen LB, Steuernagel GR (1990) Variation of milk, fat, protein and somatic cells for dairy cattle. J Dairy Sci 73, 484-493

Shalabi SI, Fox PF (1982) Influence of $\mathrm{pH}$ on the rennet coagulation of milk. J Dairy Res 49, 153-157

Siebert B, Erhardt G, Senft B (1985) Procedure for simultaneous phenotyping of genetic variants in cow's milk by isoelectric focusing. Anim Blood Groups Biochim Genet 16, 183-191

Storry JE, Ford GD (1982) Some factors affecting the post clotting development of coagulum strenght in renneted milk. J Dairy Res 49, 469-477

Storry JE, Grandison AS, Millard D, Owen AJ, Ford, GD (1983) Chemical composition and coagulating properties of rennet milks from different breeds and species of ruminants. J Dairy Res 50, 215-229

Sutton JD (1989) Altering milk composition by feeding. J Dairy Sci 72, 2801-2814

Vertès C, Hoden A (1989) Qualité fromagère des laits de vache en fonction des régimes à base d'herbe. Lait $69,197-209$

Vertès C, Hoden A, Gallard Y (1989) Effet du niveau d'alimentation sur la composition chimique et la qualité fromagère du laits de vaches Holstein et Normandes. Résultats préliminaires. INRA Prod Anim 2, 89-96

White JCD, Davies DT (1958) The relation between the chemical composition of milk and the stability of the casein complex. III.Coagulation by rennet. J Dairy Res 25,267-280 